\title{
A method for predicting hydrogen and oxygen isotope distributions across a region's river network using reach-scale environmental attributes
}

5 Bruce D. Dudley ${ }^{1}$, Jing Yang ${ }^{1}$, Ude Shankar ${ }^{1}$, and Scott Graham ${ }^{2}$

${ }^{1}$ National Institute of Water and Atmospheric Research, 10 Kyle Street, Riccarton, Christchurch 8011, New Zealand

${ }^{2}$ Manaaki Whenua - Landcare Research, 54 Gerald Street, Lincoln 7608, New Zealand

Correspondence to: Bruce D. Dudley (bruce.dudley@niwa.co.nz)

Abstract. Stable isotope ratio measurements (isotope values) of surface water provide information on hydrological processes

10 and can be used to determine provenance of hydrogen and oxygen stored in animal and plant tissues. Development of maps of the distribution of isotope values (isoscapes) for river networks is limited by methods to interpolate point measures to values for the entire network. Isotope values of precipitation and environmental characteristics that drive fractionation processes within the catchment also affect downstream reaches via flow. Many environmental characteristics, such as man-made dams, are no more likely to affect nearby unconnected reaches than distant ones. Hence, distance-based geospatial and statistical

15 interpolation methods used to develop isoscapes for precipitation and terrestrial systems are less appropriate for river networks. We used a water balance-based method, which represents patterns of surface flow and mixing, and added a regression-based correction step using catchment environmental predictors. We applied this method across the river network of New Zealand, comprising over 600,000 reaches and over 400,000 kilometres of rivers. Inputs to the model are national rainfall precipitation isoscapes, a digital elevation layer, a national river water isotope monitoring dataset (3 years of monthly sampling at 58 sites) and reach scale river environmental databases across the New Zealand river network. $\delta^{2} \mathrm{H}$ and $\delta^{18} \mathrm{O}$ isoscapes produced using this regression-based kriging method showed improved fit to validation data, compared to a model for which residuals were applied as a correction factor across the river network using ordinary kriging. The resulting river water isoscapes have potential applications in ecology, hydrology and provenance studies for which understanding of spatial variation between precipitation and surface water isotope values are required. 


\section{Introduction}

Stable hydrogen and oxygen isotope measurements in surface water provide powerful tools for hydrology, ecology and food science; uses include identifying runoff sources to rivers, quantifying land-atmosphere water fluxes, determining natal origins of migratory fish, and tracing the geographical origins of food (Kelly et al., 2005; Cable et al., 2011; Gao and Beamish, 1999; Gibson et al., 1996). Therefore, it is important to know spatially explicit distributions of hydrogen and oxygen stable isotope ratios (hereafter isotope values, following delta notation (Coplen, 2011)) for water bodies. Isotope values in rivers are strongly dependent on that of precipitation (Kendall and Coplen, 2001), mixing of water sources, and isotopic fractionation resulting from different hydrologic processes occurring at and below the land surface within their catchments. Variations in the isotope values of precipitation reflect the temperature at which condensation occurs and prior condensation as air masses are transported over land, with the general effect that:

1. Precipitation becomes more depleted in heavy isotopes at higher latitudes, and higher elevations (Dansgaard, 1964).

2. Precipitation inland tends to be more isotopically depleted than that falling at the coast (Dansgaard, 1964; Winnick et al., 2014).

40 3. At mid- to high latitudes precipitation isotope values vary seasonally with changing temperatures, becoming more enriched in summer and depleted in winter (Craig, 1961).

The isotope composition of precipitation at a site is also affected by the source of water vapour in air masses (Jouzel et al., 2013; Baisden et al., 2016; Crawford et al., 2013), and sub-cloud processes including re-evaporation (Risi et al., 2008; Winnick et al., 2014). Understanding of the processes controlling precipitation isotope values has led to the development of predictive statistical models for global-scale mapping of precipitation isotopes values that serve also to inform on spatial patterns of surface water isotope values (Bowen and Revenaugh, 2003; Bowen et al., 2011).

A range of hydrologic processes occur at and below the land surface that alter the isotope composition of surface waters relative to the isotope composition of precipitation. These include fractionation during atmospheric exchange processes at ground,

50 water and vegetation surfaces (Evaristo et al., 2015; Ehleringer and Dawson, 1992; Gat, 1996), temporal and spatial patterns of sub-surface flow (Gonfiantini et al., 1998), and mixing between isotopically distinct waters (Klaus and Mcdonnell, 2013; Mcdonnell et al., 1991). A key limitation of current approaches to modelling stable isotope values of river water is representation of these processes across river networks (Bowen et al., 2011; Brennan et al., 2016). Geostatistical interpolation methods and linear regression used for spatial modelling of precipitation are less appropriate for surface waters because some

55 landscape characteristics that alter surface water isotope values, such as dams and lakes that increase atmospheric exchange (Gibson et al., 2016; Craig, 1961), are transferred to reaches downstream, but have no impact on nearby unconnected river networks. Hence, isotope values of surface waters are controlled by a mix of geospatial dependencies and those 'dendritic' dependencies unique to river networks (Brennan et al., 2016).

The water balance model approach of Bowen et al. (2011) provides a method of mapping hydrogen and oxygen isotope ratios across river networks that incorporates variation that can be modelled with interpolation approaches, and variation that follows the 'dendritic' patterns unique to river networks. This method takes advantage of spatial and seasonal predictability of precipitation isotope values, evaporative water loss and catchment discharge. Spatial patterns of residuals between predicted (modelled) and measured (annual averages of measured stream water isotope values) are then interpolated using ordinary

65 kriging to improve models of river water isotopes. Bowen et al. (2011) note that residual adjustment using ordinary kriging only indirectly considers many of the landscape attributes that may affect stream water isotope values. These attributes include 
those that affect temporal and spatial patterns of sub-surface flow, such as catchment slope (Salama et al., 1993), and those that affect atmospheric exchange processes, such as the presence of dams and natural lakes (Halder et al., 2015; Gat, 1996). When spatial variability within the catchment is low and sampling density is high, ordinary kriging methods may be appropriate, however, New Zealand is an example of a country with relatively large distances between long-term river monitoring sites but high variation in relief and climate over relatively short distances. Under these conditions, using regression based statistical methods with databases of explanatory environmental, rather than distance-based methods, to explain hydrological variation across the reaches of river networks provides superior prediction of spatial variability (Snelder and Biggs, 2002; Hicks et al., 2011). In this paper we follow the spatio-temporal water balance model of Bowen et al. (2011) to derive of long-term water isotope values from New Zealand rivers, using precipitation isoscape coefficients of (Baisden et al., 2016), gridded meteorological data from NIWA's virtual climate station network (Tait et al., 2006; Tait, 2008), and a digital elevation map (DEM)-based river network (Snelder and Biggs, 2002). We calculate residuals between modelled surface water isotope values and values measured at 58 long-term river water sampling sites across New Zealand. We extrapolate these residuals across New Zealand using a regression method that incorporates explanatory environmental variables from the River Environment Classification database (Snelder and Biggs, 2002), Freshwater Ecosystems of New Zealand (FENZ) geodatabase (Leathwick et al., 2010), as well as GIS lake data as predictors. We compare this 'regression kriging' residual estimation with ordinary kriging (Cressie, 1992; Bowen et al., 2011). We employ the method above to develop the first complete isoscape for the rivers and streams of New Zealand.

\section{Methods}

\subsection{Water balance model for estimation of river water stable isotope values}

Our initial method to calculate long-term isotope values of river water closely followed that given by Bowen et al. (2011) to calculate their 'spatiotemporally weighted water balance model' and are only briefly summarised here. For each $5 \mathrm{~km} \times 5 \mathrm{~km}$ grid cell, we estimated monthly runoff $(\mathrm{Q})$ as the larger of precipitation minus evaporation $(\mathrm{P}-\mathrm{E})$, or $0.01 \times \mathrm{P}$; the latter estimate $(0.01 \times \mathrm{P})$ provides an estimate of dry-season and dry-region runoff (Bowen et al., 2011). We estimated the annual isotopic flux of runoff from monthly-weighted values for each cell following Eq. (1):

$$
\delta Q_{m}=\sum_{i=1}^{12}\left[\left(P_{i}-E_{i}\right) \times \delta_{i}\right]
$$

95

Where $\delta_{i}$ is the isotope value of precipitation within the grid cell at month $i$. The monthly-weighted isotopic flux $\left(\delta \mathrm{Q}_{\mathrm{m}}\right)$ is calculated by summing across all monthly values (i). Routing of gridded runoff started with a $30 \mathrm{~m}$ gridded DEM of NZ. We pit-filled the grid using Spatial Analyst in ArcGIS 10.6, then calculated flow direction next for each grid cell using the d8 method (O'callaghan and Mark, 1984), which considers flow to one of 8 adjacent cells. Values of $Q$ and $\delta Q_{m}$ in each grid cell were then accumulated downstream using the flow accumulation tool in ArcGIS.

\subsection{Model input data}

Gridded precipitation isotope values for New Zealand were generated using the monthly models of Baisden et al. (2016). We applied the regression coefficients of Baisden et al. (2016) to the geographical and climate predictor data given in their study, including elevation, latitude, pressure, solar radiation, air temperature, vapor pressure, wind speed, soil temperature at $100 \mathrm{~mm}$ depth, and an estimate of potential evapotranspiration (PET). Daily climate variables, PET and precipitation were retrieved 
from the NIWA virtual climate station network (VCSN; (Tait et al., 2006; Tait and Woods, 2007)), covering the period 19972018. Precipitation-weighted means were produced for climate drivers and coefficients were applied to yield monthly $\delta^{2} \mathrm{H}$ and $\delta^{18} \mathrm{O}$ values for precipitation. While Baisden et al. (2016) also used VCSN interpolated data in their regressions, the VCSN is regularly updated as new physical climate stations are added to or removed from the national climate network and as the spline models are periodically improved (Tait et al., 2006). Hence, we checked the results of our procedure by performing regressions between our modelled, amount-weighted monthly precipitation isotope values and measured values from the dataset of Baisden et al. (2016), comprising monthly collections from 51 sites across New Zealand between 2007 and 2009. Actual evapotranspiration (AET), as an input to the water balance model, was estimated according to the model of Porteous et

115 al. (1994) assuming a soil water storage capacity of $150 \mathrm{~mm}$ and a critical value of $50 \%$ of this capacity, above which AET was assumed to be equal to PET and below which PET was scaled linearly to zero. Digital elevation input data were sampled from a $30 \mathrm{~m}$ digital elevation model of New Zealand at the respective VCSN locations. Catchment environmental characteristics were taken from the River Environmental Classification (REC; (Snelder and Biggs, 2002)) and FENZ geodatabase (Leathwick et al., 2010).

120 A summary of contributing data sources is shown in Figure 1.

\subsection{Calculation and kriging of model residuals}

Modelled river water isotope values were compared to annual average values from 58 sites from the New Zealand River water network (NRWQN; (Davies-Colley et al., 2011)) selected to represent catchments nationally (Yang et al., 2020). The residual calculations used in this study compared predicted flow-weighted annual average values to averages of measurements. Measurements were flow-weighted monthly values at each site from April 2017-March 2020. Data from April 2017-March 2019 is published in Yang et al. (2020). For the current analysis, an additional year of data (April 2019-March 2020) was collected from all NRWQN sites following the methods of (Yang et al., 2020). Briefly, samples were taken monthly from each of the 58 sites, and river flow rates were recorded at the time when samples were collected. All samples were stored in $100 \mathrm{ml}$ tubes in insulated ice bins, keeping samples at approximately $0^{\circ} \mathrm{C}$ and in darkness in the field, and then frozen and stored at approximately $-20^{\circ} \mathrm{C}$ in the laboratory and later thawed for analyses. Isotope analyses were conducted using an isotope ratio infrared spectroscopy (IRIS) on a wavelength-scanned, cavity ring-down spectrometer (WS-CRDS) model L1102-i (Picarro, Sunnyvale, California, USA). Any variation in isotope values resulting from diurnal patterns was minimised by collection of samples at similar times of the day. River flow rates were recorded at the time when samples were collected.

The locations of monitoring stations were adjusted in ArcGIS to coincide with the nearest grid cell of the stream network. Modelled isotopic compositions were extracted from each of the grid cells corresponding to a monitoring site, and the differences between modelled and observed calculated.

To improve reach-scale predictions of water stable isotope values beyond the predictions of the water balance model, we used and compared two kriging methods, Ordinary Kriging and Regression Kriging. These two methods were used to extend calculated residuals between simulated and observed stable isotopes at our 58 validation sites across the New Zealand stream network. Ordinary Kriging, following the method of Bowen et al. (2011), only relies on spatial similarity (i.e. spatial autocorrelation) of the residuals. Regression kriging relies not only on spatial similarity, but also non-location predictors. In this case, the non-location predictors are catchment environmental variables available at sub-catchment scale across the New Zealand from the REC and FENZ geodatabases (Snelder and Biggs, 2002; Leathwick et al., 2010).

145 In Ordinary Kriging, the prediction is a weighted mean of the observations:

$$
y_{i}=\sum_{k=1}^{n} \beta_{k}(i) y_{k}^{o}
$$


where $y_{i}$ is the prediction at location i, $y_{k}^{o}$ is the $\mathrm{k}^{\text {th }}$ observations $(\mathrm{k}=1, \ldots, \mathrm{n})$, and $\beta_{k}(i)$ is the kriging weight of $y_{k}^{o}$ to $y_{i}$ which is a function of locations of $\mathrm{i}$ and observation $\mathrm{k}$ and depends on the spatial autocorrelation structure of the variable (Hengl et al., 2007).

150 In Regression Kriging, the prediction is the sum of a simple regression (normally linear regression as shown below) and the result of Ordinary Kriging:

$$
y_{i}=\sum_{j=1}^{p} \alpha_{j} x_{j}+\sum_{k=1}^{n} \beta_{k}(i) e_{k}^{o}
$$

where $x_{j}$ is the $\mathrm{j}^{\text {th }}$ environmental variable $(\mathrm{j}=1, \ldots, \mathrm{p})$ and $\alpha_{j}$ is the corresponding regression coefficient, and $e_{k}^{o}$ is the residual at kth observation after the regression.

Application of regression kriging includes two steps. The first step is to apply a simple multivariable regression aiming to select the best independent non-location variables. An initial list of over 30 potential independent variables for the regression model were selected from the REC and FENZ geodatabases based on our understanding of the hydrological processes which potentially influence stream isotope components, including geological factors (e.g. slope, elevation, aspect, drainage density and lake coverage), climate factors (e.g., precipitation and evaporation), and land cover (Yang et al., 2020; Yang et al., 2019). Table S1 includes descriptions of these variables; we use abbreviations hereafter as described in the table. Because many of these variables represent characteristics of the upstream catchment, they provide a representation of catchment-specific upstream processes (such as evaporation from wetlands, reservoirs, and lakes) that may affect river water isotope values. However, given the relatively small number of validation sites available (58), correlation analysis and stepwise regression were applied to reduce number of independent variables. From the list of independent variables in Table S1, five were selected in the regression analysis, following the "one in ten rule" (e.g. Harrell Jr (2015)), i.e. one predictive variable can be included for every ten sites in the dataset. In the second step, spatial autocorrelation is considered together with five selected variables following Equation 3, to give the prediction.

The performance of ordinary kriging and regression kriging in predicting spatial patterns of residual values was assessed across the 58 long-term river monitoring sites using k-fold cross validation (Stone, 1974). In this study, we applied LOOCV and 10fold cross-validation to assess the performance of the two kriging methods.

\subsection{Data for final model validation}

Final model validation used water isotope data collated from previously published studies of rivers across New Zealand (Lachniet et al., 2021; Kerr et al., 2015; Stewart et al., 1983; Marttila et al., 2017). The literature validation dataset is provided as a supplementary file (File S1). This validation dataset contains largely synoptic sampling data; due to a paucity of annual average values in the validation dataset we included unpublished $\delta^{2} \mathrm{H}$ and $\delta^{18} \mathrm{O}$ data from 9 river sites for which regional government staff have conducted monthly sampling over date ranges between 2017 and 2020. Water samples from these sites were stored and analysed following the methods of Yang et al. (2020) and annual average values were used in regression analyses. These sites are listed as Dudley et al. unpublished data in File S1. Because the dataset of Stewart et al. (1983) contained $\delta^{2} \mathrm{H}$ but not $\delta^{18} \mathrm{O}$ data, the $\delta^{2} \mathrm{H}$ literature validation dataset is considerably larger (464 records) than that for $\delta^{18} \mathrm{O}$ (273 records), and the $\delta^{2} \mathrm{H}$ literature validation dataset also contains a higher proportion of sites in the North Island, because the large dataset of Lachniet et al. (2021) is restricted to South Island rivers. 


\section{Results and Discussion \\ 3.1 Precipitation isotope values}

190 Our modelled estimates of long-term precipitation isotope values are a close match to those published in Baisden et al. (2016), from which we took regression coefficients; $\delta^{2} \mathrm{H}$ and $\delta^{18} \mathrm{O}$ values become increasingly enriched in northern and low elevation areas of New Zealand, with the sharpest spatial gradients at the western edges of New Zealand's central mountain ranges, which face New Zealand's prevailing West-Southwesterly winds and dominant western moisture source. Regressions between modelled, amount-weighted monthly $\delta^{2} \mathrm{H}$ values and $\delta^{2} \mathrm{H}$ values in monthly precipitation collections (i.e. the 2007-2010

195 monthly collection time series of Baisden et al.) resulted in $R^{2}=0.45$ and RMSE $=10.1 \%$ for monthly predictions and $R^{2}=$ 0.79 and $\mathrm{RMSE}=5.1 \%$ for amount-weighted average values for the full 2007-2010 timespan of field sampling. Regressions between modelled, volume-weighted monthly $\delta^{18} \mathrm{O}$ values and measured monthly precipitation $\delta^{18} \mathrm{O}$ values resulted in $R^{2}=$ 0.48 and $\mathrm{RMSE}=1.2 \%$ for monthly predictions and $R^{2}=0.80$ and RMSE $=0.55 \%$ for 2007-2010 average predictions. These fit statistics differ very slightly from those published by Baisden et al. (2016), showing improved monthly fits, but a poorer longer-term fit for $\delta^{18} \mathrm{O}$. This is likely due to updates to the climate network data used for VCSN model input, and updates to the interpolation scheme as described above.

\subsection{River water stable isotopes modelled using the water balance method}

Modelled, uncorrected estimates of long term river water isotope values for each of the 58 NRWQN stations ranged from -

$68.66 \%$ to $-32.54 \%$ (national average $-49.83 \%$ ) for $\delta^{2} \mathrm{H}$ and $-9.56 \%$ to $-5.67 \%$ (national average $-7.56 \%$ ) for $\delta^{18} \mathrm{O}$. Average (2017-2020) measured river water isotope values at these same NRWQN sites ranged from -77.01\% to $-19.75 \%$ for $\delta^{2} \mathrm{H}$ (national average $-46.38 \%$ ) and $-10.63 \%$ to $-2.85 \%$ (national average $-7.25 \%$ ) for $\delta^{18} \mathrm{O}$. The uncorrected model explained $68 \%$ of the observed variability in $\delta^{2} \mathrm{H}$ values between sites, and $64 \%$ of the observed variability in $\delta^{18} \mathrm{O}$ values between sites (Figure 2). Notably, the uncorrected model showed a tendency to under-predict both $\delta^{2} \mathrm{H}$ and $\delta^{18} \mathrm{O}$ in warmer northern and low elevation sites (i.e. at the less-negative end of the range). Model under-prediction for these stations is likely due, at least in part, to evaporative enrichment of surface waters. Since these 58 NRWQN stations extend across a large latitude and elevation gradient, rivers sampled at northern and low-elevation sites flow through catchments with substantially warmer mean annual temperatures that are likely to have led to greater evaporative enrichment. Many of the sites in northern New Zealand also have large areas of lakes and wetlands in their upstream catchments (Yang et al., 2020) contributing to greater potential for

215 evaporation.

Over-prediction of both $\delta^{2} \mathrm{H}$ and $\delta^{18} \mathrm{O}$ was apparent at some sites (Figure 2). This pattern has a precedent in areas of the continental USA with high topographic relief, where the spatially-weighted model of Bowen et al. (2011), which did not consider seasonal differences in P-E, appeared to under-predict the contribution of isotopically depleted runoff from high elevations to rivers. In that study, over-prediction was ascribed to the use of a model that did not consider seasonal differences in evapotranspiration; this issue was largely resolved using a temporally weighted model that considered these differences. In our study, this issue was most prominent in the South Island of New Zealand, which is characterised by high topographic relief, and high-elevation recharge sources dominate the flow of the majority of large rivers. However, in our study, we use a water balance model that considers seasonal differences in P-E but does not appear to have fully resolved this pattern. Potential reasons for this are, firstly, that the precipitation model we use over-estimates the isotope values of precipitation at high elevations or in leeward, rain-shadow areas; of the eight sites where predicted $\delta^{18} \mathrm{O}$ values exceed average measured $\delta^{18} \mathrm{O}$ values by $>1 \%$, seven are in alpine-fed rivers on the leeward east of New Zealand. Kerr et al. (2015) note that small streams leeward of the Southern Alps show isotopically depleted values characteristic of spillover of orographic precipitation from the 
windward west of the Southern Alps. While the linear regression approach employed in the precipitation model we used does not directly adjust for such orographic effects, it does to some extent capture areas of low $\delta^{2} \mathrm{H}$ and $\delta^{18} \mathrm{O}$ values in eastern New

230 Zealand (Baisden et al., 2016).

A second potential driver of model over-prediction of river water isotope values is surface water / groundwater interactions.

Rivers in lowland, leeward New Zealand tend to gain a significant portion of their flow from groundwater (Yang et al., 2019). Where this groundwater is dominantly derived from high-elevation recharge, gaining streams and springs tend to be depleted in stable water isotopes (Stewart et al., 2018). The (uncorrected) water balance model we employ does not consider groundwater pathways; this may result in error particularly in areas where gains from or losses to groundwater are considerable.

\subsection{Kriging of isotope residuals}

For regression kriging, simple multivariable regression applied to $\delta^{2} \mathrm{H}$ residual and $\delta^{18} \mathrm{O}$ residuals, individually, gave final lists of five independent environmental variables selected on the basis of $t$ statistics in the two linear regressions (Table 1). These variables are related to elevations (SiteElev and usCatElev), slope (usAveSlope), rainfall variability (usAnRainVar), and lake and wetland areas (usLWArea), the latter a reflection of residence time and evaporation effect. The reduced regression analyses explained over $60 \%$ of the of the uncertainty in the isotope residuals; $\mathrm{R}^{2}$ values were 0.6 and 0.66 for the $\delta^{2} \mathrm{H}$ residual and $\delta^{18} \mathrm{O}$ residual regressions, respectively. The importance of each environmental variable ( $3^{\text {rd }}$ column in Table 1$)$, ranked by t statistic, shows usLWArea, usAnRainVar and usCatElev are the 3 most sensitive variables in both $\delta^{2} \mathrm{H}$ and $\delta^{18} \mathrm{O}$ residual regressions, although the order of importance differs between the two analyses. Other variables in Table S1 sensitive to isotope residuals that were not included in regression included climatic variables (e.g. PET, AET, Precip, and usSolarRadSum). While including these variables could improve $\mathrm{R}^{2}$ values for regressions (e.g. by including annual average precipitation (Precip) as a predictor, $\mathrm{R}^{2}$ for $\delta^{2} \mathrm{H}$ and $\delta^{18} \mathrm{O}$ residuals can reach 0.76 and 0.80 , respectively). However, this led to overfitting and caused the spatial isotope prediction in the following steps to be unreliable. Once the above 5 environmental predictor variables were chosen, regression kriging was applied to estimate spatial patterns of residuals across New Zealand. The performance of ordinary kriging, and regression kriging were then evaluated with LOOCV and 10 -Fold $\mathrm{CV}$. The results of this assessment for $\delta^{18} \mathrm{O}$ residuals are shown in Figure 3. Both LOOCV and 10-Fold CV led to similar results: regression kriging simulations are scattered around the 1:1 line while those of ordinary kriging are mostly close to a horizontal line with values around 0 . There is little predictive ability for ordinary kriging, as indicated by $\mathrm{R}^{2}$ values below 0.1 for both LOOCV and 10-Fold CV. Regression kriging achieved satisfactory results, with $\mathrm{R}^{2}$ over 0.75 for both LOOCV and 10-Fold CV. These results indicate regression kriging can be reasonably used to estimate spatial distributions of isotope residuals. It is worth noting that multiple regression contributed around 0.66 and kriging contributed around 0.1 of the total $\mathrm{R}^{2}$. This emphasises the importance of the multiple regression step in this method, i.e. the first part of equation 3.

\subsection{Spatial distributions of model residuals}

260 Spatial interpolation of isotope residuals were applied to the entire national river network. Residuals interpolated using ordinary kriging (Figures 4A and 4C) show regional patterns; the water balance model tends to overpredict $\delta^{2} \mathrm{H}$ and $\delta^{18} \mathrm{O}$ values in rain-shadow areas in the east of both the North and South Islands and underpredict $\delta^{2} \mathrm{H}$ and $\delta^{18} \mathrm{O}$ values in the northern and western regions of both islands. Residuals shown in Figure 4 are calculated as the modelled minus average measured $\delta$ values for individual river reaches, so positive residuals occur where measurements were on average more depleted than the model estimate. Lower isotope values in precipitation and rivers leeward of large mountain ranges are driven by fractionation during orographic precipitation processes (Stern and Blisniuk, 2002; Poage and Chamberlain, 2001), and the patterns observed across the Southern Alps indicate that the dominant source of water to rivers in leeward areas is precipitation carried over the Alps by winds (Kerr et al., 2015). The overprediction of $\delta^{2} \mathrm{H}$ and $\delta^{18} \mathrm{O}$ values (of the water balance model) in rain-shadow 
areas indicates either greater recharge from high elevations to river flow within these regions, or local differences between actual and predicted (modelled) precipitation isotope values. We suggest that at least some of the patterns of residuals for the water balance model (Figure 4) can be accounted as a correction of the precipitation isotope model of Baisden et al. (2016) with regard to west-to-east depletion of precipitation isotope values associated with orographic rainfall across the Southern Alps. The basis of this conclusion is shown in Figure S1, in which we have plotted residuals between measured and modelled $\delta^{2} \mathrm{H}$ values for small rivers across an east to west transect through the Southern Alps (Kerr et al., 2015). The precipitation isotope model (i.e. Baisden et al., 2016) appears to underpredict $\delta^{2} \mathrm{H}$ values to the west of the main divide, and overpredict them to the east. The patterns seen in Figure 2 and Figure S1 indicate that these prediction errors were improved by the regression-kriging correction, though not fully resolved. Baisden et al. (2016) observe that the origins of air masses contributing to precipitation in New Zealand, and their transit across mountainous regions contribute strongly to spatial patterns of isotopes in precipitation; incorporation of this information in predictive models would seem a valuable step to improve precipitation and river isotope models for New Zealand. Interpretation of spatial patterns of residuals to imply spatial patterns of hydrological processes (such as evaporation, or groundwater contributions to rivers) is dependent to some degree on the accuracy of the precipitation isotope model. Where the precipitation model does not predict regional patterns well, residuals for the river water model may reflect these errors. Spatial patterns of the strongest predictors are shown in Figure S2; we believe that relationships between residuals and some predictors may reflect issues with representation of orographic effects by the precipitation model. All predictors except "usLWArea" show a strong west to east gradient; for example, areas to the east of the Southern Alps where the water balance model overpredicts river water $\delta^{2} \mathrm{H}$ and $\delta^{18} \mathrm{O}$ values have lower average catchment slopes (usAveSlp) and higher rainfall variance (usAnRainVar) than are present to the west the alps where the water balance model underpredicts river water $\delta^{2} \mathrm{H}$ and $\delta^{18} \mathrm{O}$ values. Furthermore, the significance of upstream lake and wetland area in the residuals regression can be attributed with some confidence to evaporation from surface waters with long durations of exposure to the atmosphere. Wetland systems and lakes are relatively well-spread throughout New Zealand (Cromarty and Scott, 1996); glacier-carved lakes, and artificial lakes used for hydroelectric power are common through much of the Southern Alps region of the South Island, while volcanic crater lakes are present particularly in the central-eastern regions of the North Island (Figure 1G). Notably, the presence of validation sites on rivers draining major lakes creates areas of residuals that differ from regional trends. For example, within the central North Island region validation sites are sparsely spread, and roughly half of the validation sites sit on major rivers draining two caldera lakes, Lake Taupo $\left(616 \mathrm{~km}^{2}\right)$ or Lake Tarawera $\left(41 \mathrm{~km}^{2}\right)$. Using ordinary kriging, these sites create an area of negative residuals (e.g. Figure 4C) that are applied as a correction to all nearby river reaches. This effect suggests that the application of distance-weighted kriging of residuals may be inappropriate for our validation dataset as discussed in section 3.3, where sites are sparse relative to both land area, patterns of lake distribution, and topographic relief. Regression kriging appeared to account to some extent for regional scale effects; regional patterns of overprediction in eastern rain shadow areas are represented, as are patterns of underprediction in northern and western New Zealand. However, regression kriging does not appear to create a regional pattern of negative residuals associated with lake evaporation in the central eastern North Island (Figure 4D).

\subsection{Final model validation}

To further validate the results from the original water balance model (uncorrected), ordinary kriging (OK-corrected) and regression kriging (RK-corrected), we compared model results to collated literature values from previously published studies of rivers across New Zealand (Lachniet et al., 2021; Kerr et al., 2015; Stewart et al., 1983; Marttila et al., 2017), and unpublished data from 9 sites as described in section 2.4. The validation analysis required assigning a reach identification number from the REC to each record reported in the citations. Using this approach, linear regression models between RK- 
corrected isotope predictions and all corresponding literature validation data explained 75.4 and $71.3 \%$, respectively, of the $\delta^{2} \mathrm{H}$ and $\delta^{18} \mathrm{O}$ variance. The fit for $\delta^{2} \mathrm{H}$ is shown in Figure 5C. Root mean squared errors (RMSE) were 6.2\%o for $\delta^{2} \mathrm{H}$ on 416 degrees of freedom and $0.67 \%$ for $\delta^{18} \mathrm{O}$ on 221 degrees of freedom. Datasets incorporating repeat sampling of stable isotopes in New Zealand river water are scarce; only 23 of the $418 \delta^{2} \mathrm{H}$ records in the literature validation dataset represent

315 annual averages of monthly sampling. The 186 river samples from the South Island rivers dataset of Lachniet et al. (2021) were collected within the month of November, within the austral spring snow-melt period; South Island river water isotope values at this time are generally below the annual average (Yang et al., 2020; Marttila et al., 2017). Hence, we would expect our model predictions at sites from high latitudes with snowmelt influence to be generally more isotopically enriched than our literature validation dataset. This effect appears strongest in the uncorrected model results. When smaller rivers (Strahler order $<3$ where larger seasonal fluctuations in isotope values would be expected) were removed from the analysis, the fit of the final model improved, explaining $80.0 \%$ and $74.2 \%$, respectively, of the $\delta^{2} \mathrm{H}$ and $\delta^{18} \mathrm{O}$ variance across the literature validation dataset, with root mean squared errors (RMSE) of 5.7\% for $\delta^{2} \mathrm{H}$ on 329 degrees of freedom and $0.62 \%$ for $\delta^{18} \mathrm{O}$ on 175 degrees of freedom. The most appropriate sites for validation of our model were those 23 sites for which long-term monthly sampling records are available, enabling us to compare predicted and measured annual average values. At these sites, the model explained $90.6 \%$ of the $\delta^{2} \mathrm{H}$ variance across the dataset. Root mean squared error (RMSE) was $2.99 \%$ for $\delta^{2} \mathrm{H}$ on 21 degrees of freedom (Figure 5D).

While comparison of modelled annual average values to the full validation dataset containing predominantly single-sample values from river reaches (Figures 5A-5C) shows relatively poor model fits compared to those for long-term measurements (Figure 5D), these comparisons serve to demonstrate improvement from the uncorrected and ordinary-kriging-corrected models to the final, regression-kriging corrected model. We attribute this improvement both to the representation of regional trends in residuals (such as the issue with representation of orographic rainfall effects described above), but also to improved representation of evaporation processes that can be made using a dendritic river network model (Brennan et al., 2016).

\subsection{Patterns and drivers of final model performance}

Patterns of precipitation isotopes, runoff and evaporation from surface water are the dominant drivers of $\delta^{2} \mathrm{H}$ and $\delta^{18} \mathrm{O}$ values in rivers

340 Across New Zealand, spatial and temporal patterns of $\delta^{2} \mathrm{H}$ and $\delta^{18} \mathrm{O}$ in precipitation and runoff are dominant drivers of $\delta^{2} \mathrm{H}$ and $\delta^{18} \mathrm{O}$ in river water (Figure 6). The (uncorrected) water balance model, which explicitly represents these factors, explained much of the variance present in our long-term river water dataset. For example, major patterns of depletion in precipitation isotopes with increasing latitude and elevation were carried through into predictions for rivers and passed downstream using the REC river network (Figures 6A and 6D). However, systematic bias was apparent; when compared to measurements from

345 river monitoring sites, the spatiotemporal water balance model showed a tendency to underpredict river water isotope values at the enriched end of the range of validation measurements and overpredict at the depleted end of this range (Figure 2).

\section{Regression kriging residual corrections improve models of $\delta^{2} \mathrm{H}$ and $\delta^{18} \mathrm{O}$ values in rivers}

Across the rivers of New Zealand, a water balance model corrected using regression kriging of residuals provided improved fits to measurements, compared to a model that used ordinary kriging interpolation of residuals between validation sites. 
Patterns of residuals across the validation site network showed distinct patterns which we attribute to orographic rainfall effects (Kerr et al., 2015; Purdie et al., 2010), and the position of lakes and wetlands in upstream catchments (Yang et al., 2020; Halder et al., 2015). The effect of lakes and wetlands is an example of how landscape processes control $\delta^{2} \mathrm{H}$ and $\delta^{18} \mathrm{O}$ values in rivers; three factors combine to make regression kriging a particularly appropriate method to represent these processes. Firstly, lakes and rivers do not cluster predictably across New Zealand, and secondly, their effects are confined to downstream reaches. Thus, a modelling approach that considers the dendritic nature of river networks in this correction step is likely to better account for this process than one which corrects based on Euclidean distance (Brennan et al., 2016). Using a term for upstream ake and wetland areas in reach-scale regression-kriging incorporates enrichment effects of lakes and transfers this effect downstream while allowing for mixing. Thirdly, distances between validation sites in the NRWQN network are great, relative to the likely downstream extent of enrichment effects from lakes and wetlands. This raises the likelihood that corrections based on distance weighting will extend outside of the extent to where their true effect will take place. Representation of evaporation effects in the final ordinary-kriging and regression-kriging corrected models is shown using the example of the Lake Tarawera region in Figure 7. River water observed in the NRWQN validation dataset at the lake outflow is enriched in $\delta^{2} \mathrm{H}$ and $\delta^{18} \mathrm{O}$ relative to upstream precipitation and spatiotemporal model predictions, which do not account for evaporation. Using ordinary kriging, the correction factor based on the residual at the lake outflow site is applied to all nearby reaches and extends outside the catchment boundaries. Using regression kriging correction, the residual correction is passed only to downstream reaches. Both the ordinary kriging and regression kriging approaches to residual correction resulted in partial correction of bias ssociated with orographic rainfall effects, however spatial extents of the corrections in leeward New Zealand differ between the two kriging methods (Figure 4). This reflects the data available to predict residuals for both methods; while the ordinary kriging method in limited by the distribution of (and lack of) validation sites across high-elevation areas of southern New Zealand, using regression kriging the correction could be applied at reach scale via factors that co-vary with orographic effects (e.g. annual rainfall variance and catchment elevation, Table 1). Sharp changes in isotope values of small rivers (Kerr et al., 2015) and snowfall (Purdie et al., 2010) observed across the main divide of the Southern Alps have been associated with orographic effects. That the regression kriging correction method can apply residuals using geographical and climatological gradients that co-vary with orographic weather patterns may partly explain improved fits of this model to river water measurements nationally.

\section{Regression kriging is vulnerable to overfitting and extrapolation}

As mentioned in section 3.3, there are more than five environmental factors in the river network datasets that are spatially correlated with patterns of isotope residuals. However, it is dangerous to include all sensitive factors in regression kriging as it may cause the problem of overfitting, which is very common in regression analysis and machine learning. Machine learning methods often uses cross-validation techniques to solve the overfitting problem. In this study, there are only 58 sites which is insufficient for application of either of data-intensive machine learning methods or nonlinear regression, which increase the number of regression coefficients to fit. Instead, we focused on the five most sensitive environmental factors, following the "one in ten rule". Our results indicate this rule was appropriate for improving model performance and avoided overfitting; the addition of one more predictor in the regression model caused a wider and unreasonable range of isotope estimates in subsequent national predictions. Extrapolation was another problem we encountered in preliminary regression analysis, as the training dataset did not cover the entire range of values for all catchment characteristics. To nullify this effect, we excluded reaches from the final model where the environmental characteristics of those reaches were outside of the range of the training dataset (e.g. Strahler order 1 streams with usLWArea greater than 0.3 ). Solutions to overfitting and extrapolation could include adding isotope sampling sites, and increasing the range of environmental conditions across sampling sites (e.g. setting up river monitoring sites with upstream wetland areas approaching 1), or, for extrapolation, removing reaches from the final isoscape which have values for predictor variables substantially outside the range present across validation sites. 
Improved understanding of patterns of precipitation isotope values can improve understanding of hydrological processes across landscapes

Spatial patterns of residuals, and predictors of residuals from the spatiotemporal water balance modelling approach could potentially be applied as an investigative tool to describe flow pathways, or evaporation processes (Bowen et al., 2011). Regression kriging of these residuals allowed us to identify a suite of catchment environmental variables that were the best predictors of spatial patterns of residuals. However, as described above, patterns of residuals shown in our study are driven to some extent by systematic bias in high-elevation precipitation isotope input data. New Zealand's topographic relief creates widely divergent isotope values of precipitation isotopes depending on moisture sources (Purdie et al., 2010; Baisden et al., 2016). These factors are difficult to capture with empirical models of precipitation isotopes of the kind used in this study (Bowen, 2010), however potential improvements to the precipitation isotope model could be made by incorporating highfrequency and event-based sampling, including back-trajectory calculations, and adjusting predictions based on spatial patterns of residuals (Bowen and Revenaugh, 2003; Baisden et al., 2016). Improved regional precipitation isotope models are likely to improve the performance of process-based isotope hydrology models, such as the Isotope-enabled coupled catchment-lake water balance model (Belachew et al., 2016), that are designed to quantify hydrological fluxes (e.g. between rivers, lakes and groundwater) using water isotope data.

\section{Final conclusions and implications}

We have successfully produced isoscapes of $\delta^{2} \mathrm{H}$ and $\delta^{18} \mathrm{O}$ for the river network of New Zealand by employing a water balancebased model, enhanced by a regression kriging method to capture catchment characteristics not accounted for by the simple water balance. Although the final model performs well, future research is needed to improve model input data and identify the processes underlying spatial patterns of residuals identified by regression kriging. Further inclusion of these processes which contribute to fractionation and source mixing will reduce the need for correction methods, which are descriptive of current patterns, but may not have predictive value with changing climate and hydrological modification.

Our results have important implications for studies of providence and migration that employ these stable isotopes as tracers, as spatial patterns of $\delta^{2} \mathrm{H}$ and $\delta^{18} \mathrm{O}$ in river waters across New Zealand show distinct differences from patterns of precipitation. Differences between precipitation and river water isotope values are particularly evident across elevation gradients; New

425 Zealand's high central mountain ranges create strong elevation gradients in precipitation isotopes, and lowland regions receiving more isotopically enriched rainfall are intersected by alpine-fed rivers bearing isotopically depleted water. Understanding how isotopic values vary in water sources for biota across elevation gradients may be of particular benefit to those studies that attempt to attribute organic material (such as sediment-bound organic material transported in rivers) to particular elevation bands (Upadhayay et al., 2017; Feakins et al., 2016). Development of reach-specific predictions for water stable isotopes may also benefit ecological studies that examine movement of aquatic organisms (e.g. Brennan et al. (2015)); fine-scale study of animal movements across river networks can benefit from maps of river water isotope variation across similarly fine spatial scales.

\section{Code and data availability}

Modelled river water isotope values generated as described in this paper are available for download via NIWA's NZ River Maps site at https://shiny.niwa.co.nz/nzrivermaps/ 
https://doi.org/10.5194/hess-2021-424

Preprint. Discussion started: 23 August 2021

(c) Author(s) 2021. CC BY 4.0 License.

River water measurements for model correction can be downloaded from the Global Network of Isotopes in Rivers (GNIR) database of the International Atomic Energy Agency (IAEA) through the WISER portal (Water Isotope System for Data 440 Analysis, Visualization and Electronic Retrieval).

A compiled literature validation data file used to produce Figure 6 is provided as supplementary file S1.

Environmental predictor datasets and code used in this work are available on request from the authors.

\section{Author Contributions}

BDD, JY and US contributed to project conceptualization, methodology, investigation, data curation and formal analysis.

BDD, JY and US contributed to writing and editing of the original draft. SG contributed to methodology, formal analysis, data curation and editing of the original draft. BDD led project administration.

\section{Competing interests}

No competing interests

\section{Acknowledgements}

450 We thank Russell Frew for access to data from the national precipitation isotope dataset reported in Baisden et al. (2016). We thank Troy Baisden and Liz Keller for advice on re-creation and implementation of their precipitation isotope model. We thank all the many people who collected the water samples that we used to improve our model, and Kelsey Montgomery and Oonagh Daly for sample analysis. 


\section{References}

Baisden, W. T., Keller, E. D., Van Hale, R., Frew, R. D., and Wassenaar, L. I.: Precipitation isoscapes for New Zealand: enhanced temporal detail using precipitation-weighted daily climatology, Isotopes in Environmental and Health Studies, 52, 343-352, $460 \quad 10.1080 / 10256016.2016 .1153472,2016$.

Belachew, D. L., Leavesley, G., David, O., Patterson, D., Aggarwal, P., Araguas, L., Terzer, S., and Carlson, J.: IAEA Isotope-enabled coupled catchment-lake water balance model, IWBMIso: description and validation, Isotopes in Environmental and Health Studies, 52, 427442, 10.1080/10256016.2015.1113959, 2016.

Bowen, G. J.: Statistical and geostatistical mapping of precipitation water isotope ratios, in: Isoscapes, Springer, 139-160, 2010.

465 Bowen, G. J. and Revenaugh, J.: Interpolating the isotopic composition of modern meteoric precipitation, Water resources research, 39, 2003.

Bowen, G. J., Kennedy, C. D., Liu, Z., and Stalker, J.: Water balance model for mean annual hydrogen and oxygen isotope distributions in surface waters of the contiguous United States, Journal of Geophysical Research: Biogeosciences, 116, 2011.

Brennan, S. R., Torgersen, C. E., Hollenbeck, J. P., Fernandez, D. P., Jensen, C. K., and Schindler, D. E.: Dendritic network models:

470 Improving isoscapes and quantifying influence of landscape and in-stream processes on strontium isotopes in rivers, Geophysical Research Letters, 43, 5043-5051, 2016.

Brennan, S. R., Zimmerman, C. E., Fernandez, D. P., Cerling, T. E., McPhee, M. V., and Wooller, M. J.: Strontium isotopes delineate finescale natal origins and migration histories of Pacific salmon, Science advances, 1, e1400124, 2015.

Cable, J., Ogle, K., and Williams, D.: Contribution of glacier meltwater to streamflow in the Wind River Range, Wyoming, inferred via a

475 Bayesian mixing model applied to isotopic measurements, Hydrological Processes, 25, 2228-2236, 2011.

Coplen, T. B.: Guidelines and recommended terms for expression of stable-isotope-ratio and gas-ratio measurement results, Rapid Communications in Mass Spectrometry, 25, 2538-2560, https://doi.org/10.1002/rcm.5129, 2011.

Craig, H.: Isotopic variations in meteoric waters, Science, 133, 1702-1703, 1961.

Crawford, J., Hughes, C. E., and Parkes, S. D.: Is the isotopic composition of event based precipitation driven by moisture source or synoptic

480 scale weather in the Sydney Basin, Australia?, Journal of Hydrology, 507, 213-226, 2013.

Cressie, N.: Statistics for spatial data, Terra Nova, 4, 613-617, 1992.

Cromarty, P. and Scott, D. A.: A directory of wetlands in New Zealand, Department of Conservation, Wellington, New Zealand 1996.

Dansgaard, W.: Stable isotopes in precipitation, Tellus, 16, 436-468, 1964.

Davies-Colley, R. J., Smith, D. G., Ward, R. C., Bryers, G. G., McBride, G. B., Quinn, J. M., and Scarsbrook, M. R.: Twenty Years of New

485 Zealand's National Rivers Water Quality Network: Benefits of Careful Design and Consistent Operation1, JAWRA Journal of the American Water Resources Association, 47, 750-771, 10.1111/j.1752-1688.2011.00554.x, 2011.

Ehleringer, J. R. and Dawson, T. E.: Water uptake by plants: perspectives from stable isotope composition, Plant, Cell \& Environment, 15 , 1073-1082, 10.1111/j.1365-3040.1992.tb01657.x, 1992.

Evaristo, J., Jasechko, S., and McDonnell, J. J.: Global separation of plant transpiration from groundwater and streamflow, Nature, 525, 91-

$490+, 10.1038 /$ nature $14983,2015$.

Feakins, S. J., Bentley, L. P., Salinas, N., Shenkin, A., Blonder, B., Goldsmith, G. R., Ponton, C., Arvin, L. J., Wu, M. S., and Peters, T.: Plant leaf wax biomarkers capture gradients in hydrogen isotopes of precipitation from the Andes and Amazon, Geochimica et Cosmochimica Acta, 182, 155-172, 2016.

Gao, Y. and Beamish, R.: Isotopic composition of otoliths as a chemical tracer in population identification of sockeye salmon (Oncorhynchus

495 nerka), Canadian Journal of Fisheries and Aquatic Sciences, 56, 2062-2068, 1999.

Gat, J. R.: Oxygen and hydrogen isotopes in the hydrologic cycle, Annual Review of Earth and Planetary Sciences, 24, 225-262, 1996.

Gibson, J., Edwards, T., and Prowse, T. D.: Development and validation of an isotopic method for estimating lake evaporation, Hydrological Processes, 10, 1369-1382, 1996.

Gibson, J. J., Birks, S. J., and Yi, Y.: Stable isotope mass balance of lakes: a contemporary perspective, Quaternary Science Reviews, 131,

500 316-328, https://doi.org/10.1016/i.quascirev.2015.04.013, 2016

Gonfiantini, R., Fröhlich, K., Araguás-Araguás, L., and Rozanski, K.: Chapter 7 - Isotopes in Groundwater Hydrology, in: Isotope Tracers in Catchment Hydrology, edited by: Kendall, C., and McDonnell, J. J., Elsevier, Amsterdam, 203-246, https://doi.org/10.1016/B978-0-44481546-0.50014-8, 1998

Halder, J., Terzer, S., Wassenaar, L., Araguás-Araguás, L., and Aggarwal, P.: The Global Network of Isotopes in Rivers (GNIR): integration

505 of water isotopes in watershed observation and riverine research, Hydrology and Earth System Sciences, 19, 3419-3431, 2015.

Harrell Jr, F. E.: Regression modeling strategies: with applications to linear models, logistic and ordinal regression, and survival analysis, Springer2015.

Hicks, D. M., Shankar, U., McKerchar, A. I., Basher, L., Lynn, I., Page, M., and Jessen, M.: Suspended sediment yields from New Zealand rivers, Journal of Hydrology (New Zealand), 81-142, 2011.

510 Jouzel, J., Delaygue, G., Landais, A., Masson-Delmotte, V., Risi, C., and Vimeux, F.: Water isotopes as tools to document oceanic sources of precipitation, Water Resources Research, 49, 7469-7486, 2013.

Kelly, S., Heaton, K., and Hoogewerff, J.: Tracing the geographical origin of food: The application of multi-element and multi-isotope analysis, Trends in Food Science \& Technology, 16, 555-567, 2005.

Kendall, C. and Coplen, T. B.: Distribution of oxygen-18 and deuterium in river waters across the United States, Hydrological processes,

515 15, 1363-1393, 2001.

Kerr, T., Srinivasan, M., and Rutherford, J.: Stable water isotopes across a transect of the Southern Alps, New Zealand, Journal of Hydrometeorology, 16, 702-715, 2015.

Klaus, J. and McDonnell, J.: Hydrograph separation using stable isotopes: Review and evaluation, Journal of Hydrology, 505, 47-64, 2013. Lachniet, M. S., Moy, C. M., Riesselman, C., Stephen, H., and Lorrey, A. M.: Climatic and Topographic Control of the Stable Isotope Values

520 of Rivers on the South Island of New Zealand, Paleoceanography and Paleoclimatology, 36, e2021PA004220, https://doi.org/10.1029/2021PA004220, 2021.

Leathwick, J. R., West, D., Gerbeaux, P., Kelly, D., Robertson, H., Brown, D., Chadderton, W., and Ausseil, A.-G.: Freshwaters of New Zealand (FENZ) geodatabase, 2010. 
Marttila, H., Dudley, B., Graham, S., and Srinivasan, M.: Does transpiration from invasive stream side willows dominate low-flow 525 conditions? An investigation using hydrometric and isotopic methods in a headwater catchment, Ecohydrology, 11, e1930, 2017.

McDonnell, J. J., Stewart, M. K., and Owens, I. F.: Effect of Catchment-Scale Subsurface Mixing on Stream Isotopic Response, Water Resources Research, 27, 3065-3073, 10.1029/91wr02025, 1991.

O'Callaghan, J. F. and Mark, D. M.: The extraction of drainage networks from digital elevation data, Computer vision, graphics, and image processing, 28, 323-344, 1984

530 Poage, M. A. and Chamberlain, C. P.: Empirical relationships between elevation and the stable isotope composition of precipitation and surface waters: considerations for studies of paleoelevation change, American Journal of Science, 301, 1-15, 2001.

Porteous, A. S., Basher, R. E., and Salinger, M. J.: Calibration and performance of the single-layer soil water balance model for pasture sites, New Zealand Journal of Agricultural Research, 37, 107-118, 10.1080/00288233.1994.9513047, 1994.

Purdie, H., Bertler, N., Mackintosh, A., Baker, J., and Rhodes, R.: Isotopic and elemental changes in winter snow accumulation on glaciers

535 in the Southern Alps of New Zealand, Journal of climate, 23, 4737-4749, 2010.

Risi, C., Bony, S., and Vimeux, F.: Influence of convective processes on the isotopic composition $(\delta 18 \mathrm{O}$ and $\delta \mathrm{D})$ of precipitation and water vapor in the tropics: 2. Physical interpretation of the amount effect, Journal of Geophysical Research: Atmospheres, 113, $10.1029 / 2008$ jd009943, 2008

Salama, R. B., Farrington, P., Bartle, G. A., and Watson, G. D.: Distribution of recharge and discharge areas in a first-order catchment as

540 interpreted from water level patterns, Journal of Hydrology, 143, 259-277, https://doi.org/10.1016/0022-1694(93)90195-F, 1993.

Snelder, T. H. and Biggs, B. J.: Multiscale river environment classification for water resources management, JAWRA Journal of the American Water Resources Association, 38, 1225-1239, 2002.

Stern, L. A. and Blisniuk, P. M.: Stable isotope composition of precipitation across the southern Patagonian Andes, Journal of Geophysical Research: Atmospheres, 107, ACL 3-1-ACL 3-14, https://doi.org/10.1029/2002JD002509, 2002.

545 Stewart, M. K., Cox, M. A., James, M. R., and Lyon, G. L.: Deuterium in New Zealand rivers and streams, Institute of Nuclear Sciences Lower Hutt: DSIR, Institute of Nuclear Sciences, 42, 1983.

Stewart, M. K., Morgenstern, U., Tsujimura, M., Gusyev, M. A., Sakakibara, K., Imaizumi, Y., Rutter, H., Raaij, R. v. d., Etheridge, Z., Scott, L., and Cox, S. C.: Mean residence times and sources of Christchurch springs, 2, New Zealand Hydrological Society, 81-94 pp., 10.3316/informit.379745659058702, 2018.

550 Stone, M.: Cross-Validation and Multinomial Prediction, Biometrika, 61, 509-515, DOI 10.1093/biomet/61.3.509, 1974.

Tait, A.: Future projections of growing degree days and frost in New Zealand and some implications for grape growing, Weather and Climate, $28,17-36,2008$

Tait, A. and Woods, R.: Spatial Interpolation of Daily Potential Evapotranspiration for New Zealand Using a Spline Model, Journal of Hydrometeorology, 8, 430-438, 10.1175/jhm572.1, 2007.

555 Tait, A., Henderson, R., Turner, R., and Zheng, X.: Thin plate smoothing spline interpolation of daily rainfall for New Zealand using a climatological rainfall surface, International Journal of Climatology: A Journal of the Royal Meteorological Society, 26, 2097-2115, 2006. Upadhayay, H. R., Bodé, S., Griepentrog, M., Huygens, D., Bajracharya, R. M., Blake, W. H., Dercon, G., Mabit, L., Gibbs, M., Semmens, B. X., Stock, B. C., Cornelis, W., and Boeckx, P.: Methodological perspectives on the application of compound-specific stable isotope fingerprinting for sediment source apportionment, Journal of Soils and Sediments, 17, 1537-1553, 10.1007/s11368-017-1706-4, 2017.

560 Winnick, M. J., Chamberlain, C. P., Caves, J. K., and Welker, J. M.: Quantifying the isotopic 'continental effect', Earth and Planetary Science Letters, 406, 123-133, 2014.

Yang, J., Griffiths, J., and Zammit, C.: National classification of surface-groundwater interaction using random forest machine learning technique, River Research and Applications, 35, 932-943, 2019.

Yang, J., Dudley, B. D., Montgomery, K., and Hodgetts, W.: Characterizing spatial and temporal variation in ${ }^{18} \mathrm{O}$ and ${ }^{2} \mathrm{H}$ content of New

565 Zealand river water for better understanding of hydrologic processes, Hydrological Processes, https://doi.org/10.1002/hyp.13962, 2020. 

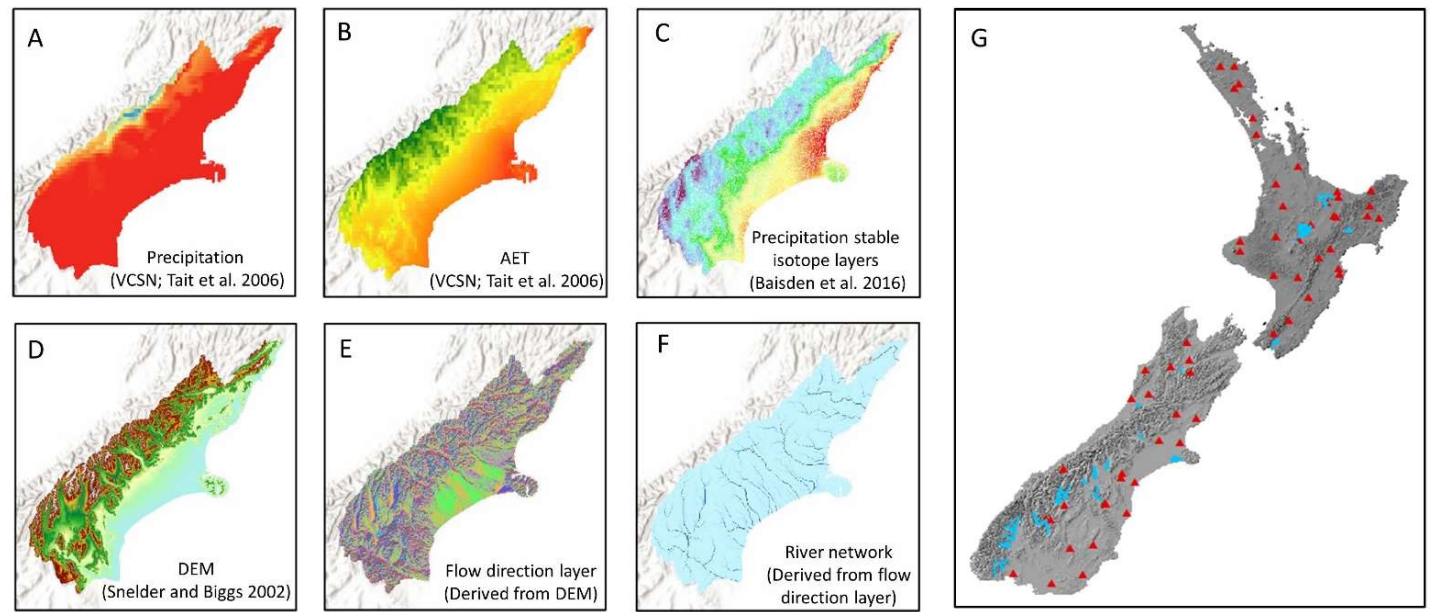

Figure 1. GIS layers and data sources used in model development. Panels A-F show GIS layers used for water balance modelling, plotted over the Canterbury region in New Zealand's South Island. Precipitation, Actual Evapotranspiration (AET), and stable isotope values of precipitation (panels A-C) are used to calculate catchment-scale flow-weighted isotope values of recharge $(\delta \mathrm{Q}$, i.e. flow * isotope $\delta$ value)). The river network $(\mathrm{F})$ is derived from the DEM (D) and flow direction (E) layers by setting a suitable flow accumulation threshold. Catchment $\delta Q$ values are routed downstream through the river network to generate reach-scale estimates of $\delta^{2} \mathrm{H}$ and $\delta^{18} \mathrm{O}$. Panel G shows river water isotope measurement sites (triangle) used for model correction, and major lakes (blue area). 

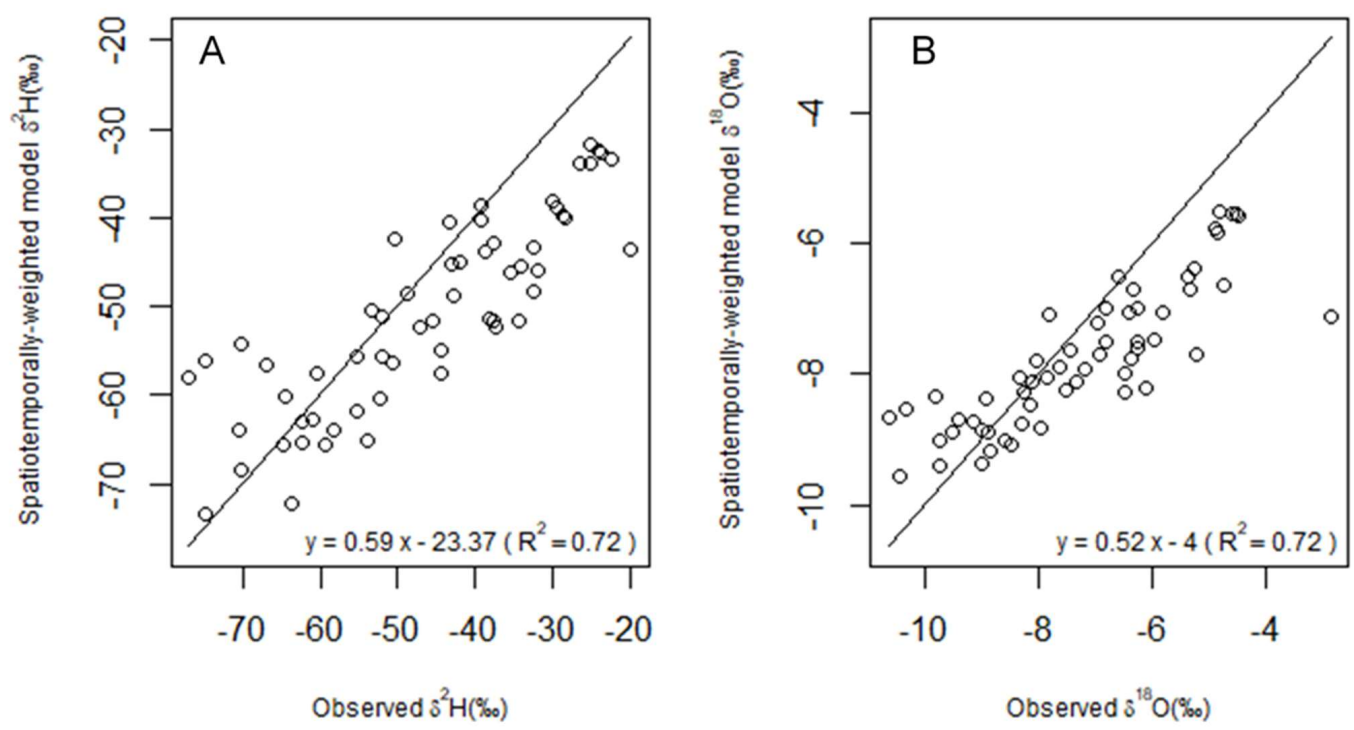

Figure 2. Relationship between modelled and observed $\delta^{2} \mathrm{H}\left(\right.$ Panel A) and $\delta^{18} \mathrm{O}$ (Panel B) at 58 long-term river water monitoring sites across New Zealand. Modelled isotopes were the long-term averages of simulated isotopes computed following the water balance model approach of Bowen et al. (2011). The solid line shows a 1:1 fit. The modelled tends to overpredict river water isotope at the more-negative end of the range (e.g. at high-latitude cooler southern sites) and under-predict at the less-negative end of the range (e.g. warmer, northern sites). 

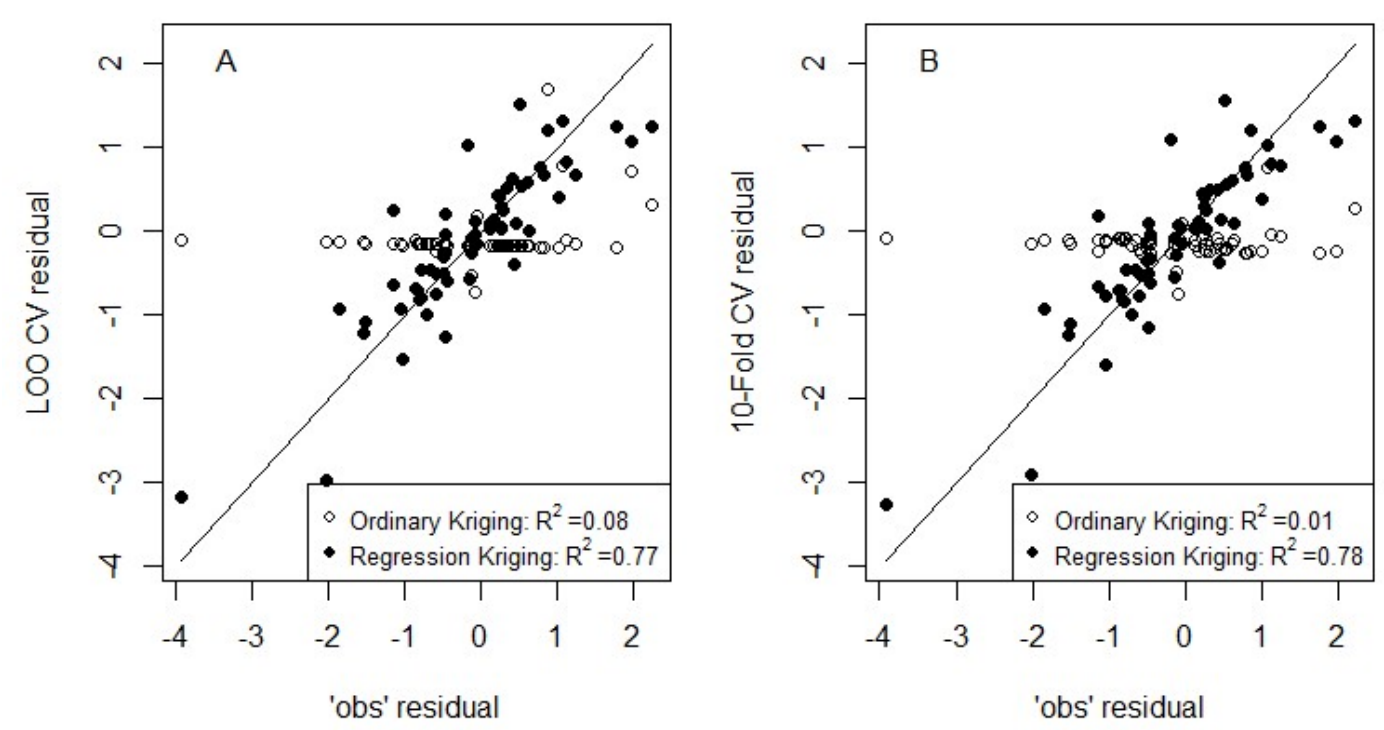

Figure 3. Comparison between observed residuals and spatial predictions of residuals made using two interpolation methods - Ordinary Kriging and Regression Kriging. Observed residuals are differences between spatiotemporal model predictions of $\delta^{18} \mathrm{O}$, and measurements from 58 long term river monitoring sites across New Zealand. Comparison with estimates of residuals generated using Leave-One-Out Cross-Validation (A) and 10-fold cross validation (B) suggests improved fit of regression kriging, relative to ordinary kriging. 

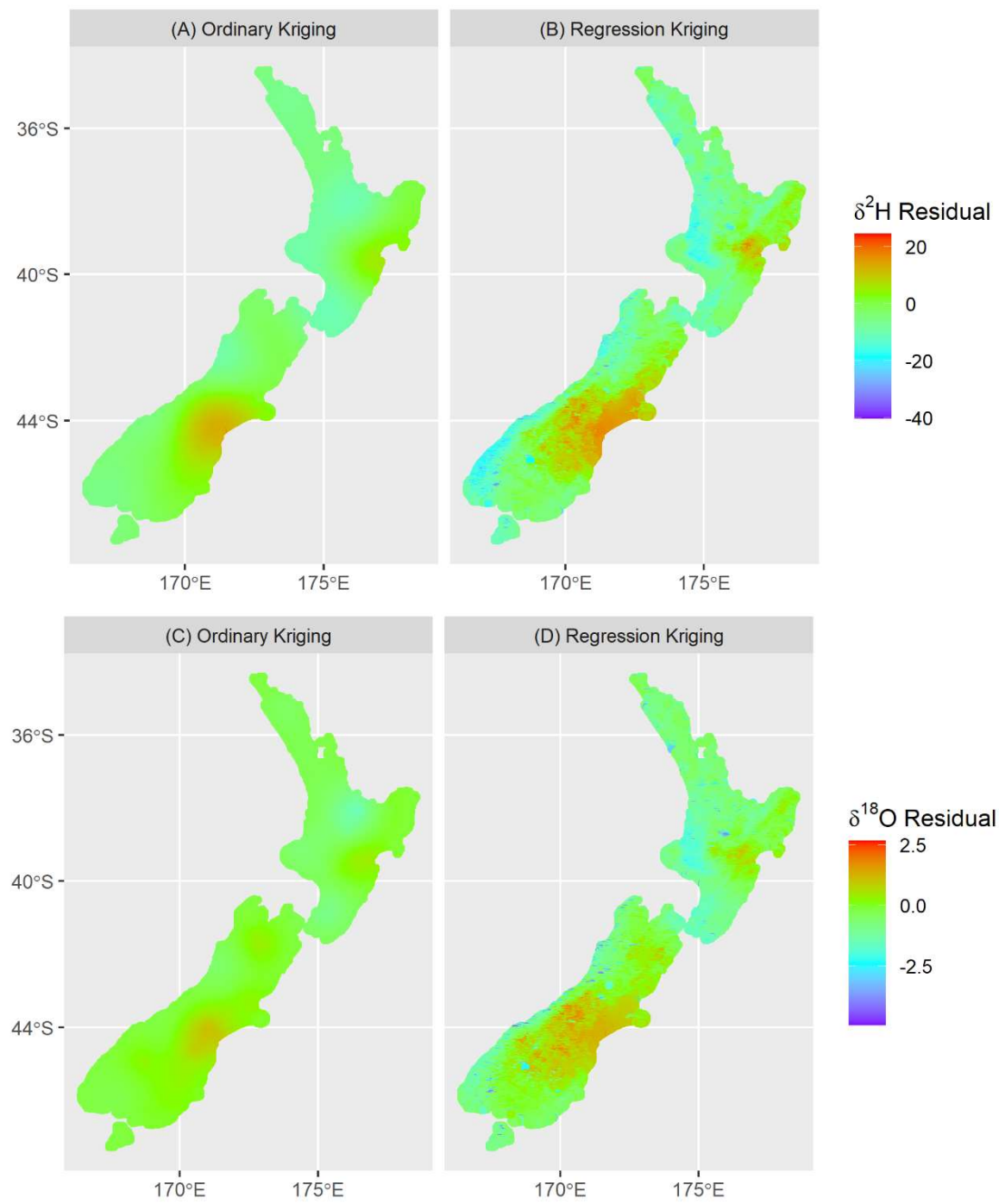

Figure 4. Distribution of isotope residuals (i.e. difference between modelled and observed isotopes) from ordinary Kriging (A and $\mathrm{C}$ ), and regression Kriging (B and D). Positive values equate to a negative adjustment of river $\delta^{2} \mathrm{H}$ and $\delta^{18} \mathrm{O}$ values from the water balance model, as seen in leeward (eastern) areas of both the North and South Island. Ordinary kriging results in regional zones of negative isotope residuals around validation sites downstream from lakes and wetlands (such as in the central North Island), while regression kriging predicts negative isotope residuals in low-elevation western areas, as well as in all lakes and wetlands and their downstream reaches. 
https://doi.org/10.5194/hess-2021-424

Preprint. Discussion started: 23 August 2021

(c) Author(s) 2021. CC BY 4.0 License.

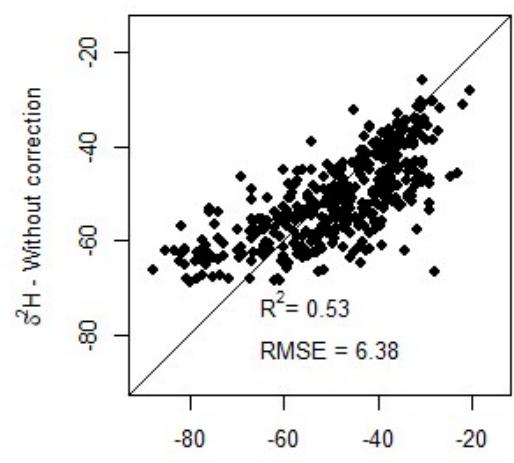

$\delta^{2} \mathrm{H}-$ Measured

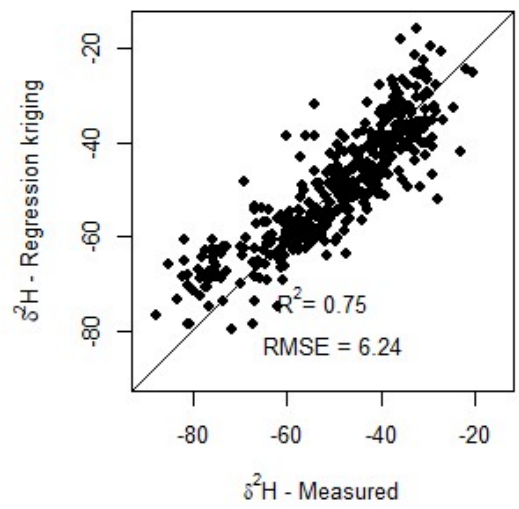

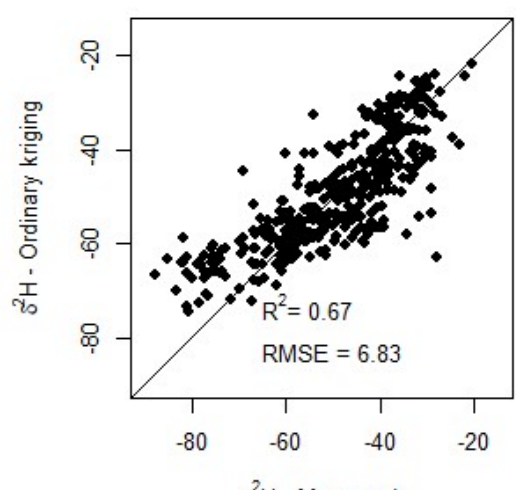

$\delta^{2} \mathrm{H}-$ Measured

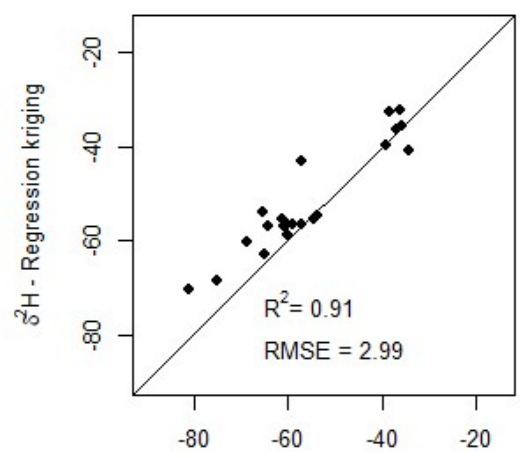

$\delta^{2} \mathrm{H}$ - Measured, annual average

Figure 5. Comparison of literature values of water $\delta^{2} \mathrm{H}$ across New Zealand rivers with predicted long-term average $\delta^{2} \mathrm{H}$ values

from: the uncorrected water balance model (A); ordinary kriging corrected model (B); and regression kriging corrected model

(C). Panel D shows a comparison between predictions of the regression kriging corrected model with mean annual measured values at sites with $>1$ year of monthly data. Lines show a 1:1 relationship. 
https://doi.org/10.5194/hess-2021-424

Preprint. Discussion started: 23 August 2021

(c) Author(s) 2021. CC BY 4.0 License.
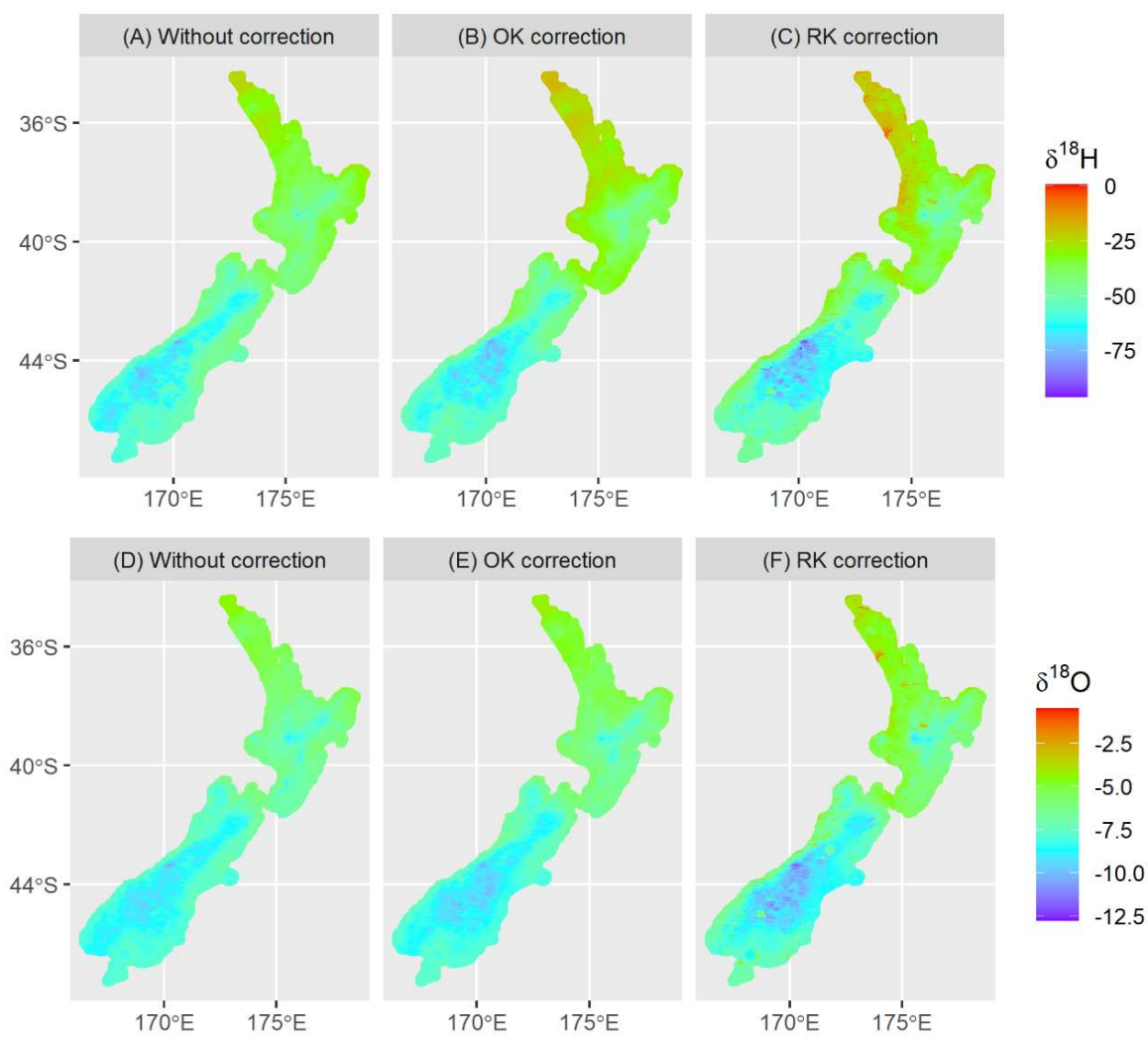

620 Figure 6. Predicted $\delta^{2} \mathrm{H}$ and $\delta^{18} \mathrm{O}$ of surface water of New Zealand. Panels A and D show uncorrected values from the water balance model. Panels B and E gives residual-corrected values based on ordinary Kriging (OK correction). Panel C and F gives residual-corrected values based on regression Kriging (RK correction). 
https://doi.org/10.5194/hess-2021-424

Preprint. Discussion started: 23 August 2021

(c) Author(s) 2021. CC BY 4.0 License.
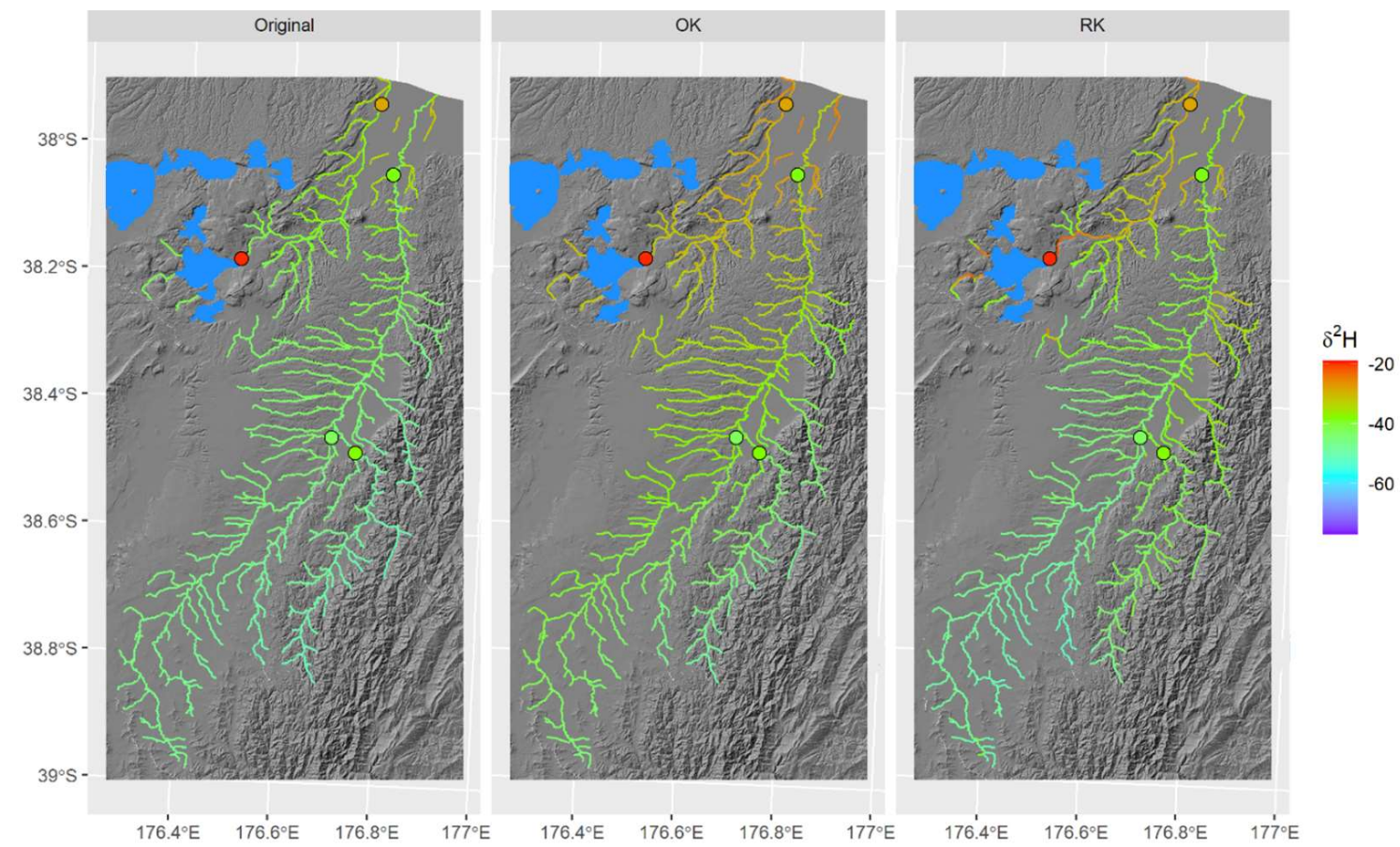

Figure 7. Comparison of modelled $\delta 2 \mathrm{H}$ values of river water across two neighbouring North Island basins (Tarawera basin and Rangitaiki basin). Higher $\delta 2 \mathrm{H}$ values from $2 \mathrm{H}$-enriched precipitation lower in these catchments are represented by the water balance model ('Original' panel A). Residual correction using ordinary kriging (OK) extends the enrichment effect of Lake Tarawera (top left of each panel) across the entire region. Using regression kriging (RK), the lake enrichment is mostly confined to downstream reaches. Points denote the locations and observed $\delta 2 \mathrm{H}$ values at the gauging sites. 
https://doi.org/10.5194/hess-2021-424

Preprint. Discussion started: 23 August 2021

(c) Author(s) 2021. CC BY 4.0 License.

Tables

635

Table 1. Selected environmental variables and related information, and importance ranks in the regression for $\delta^{2} \mathrm{H}$ and $\delta^{18} \mathrm{O}$ residuals

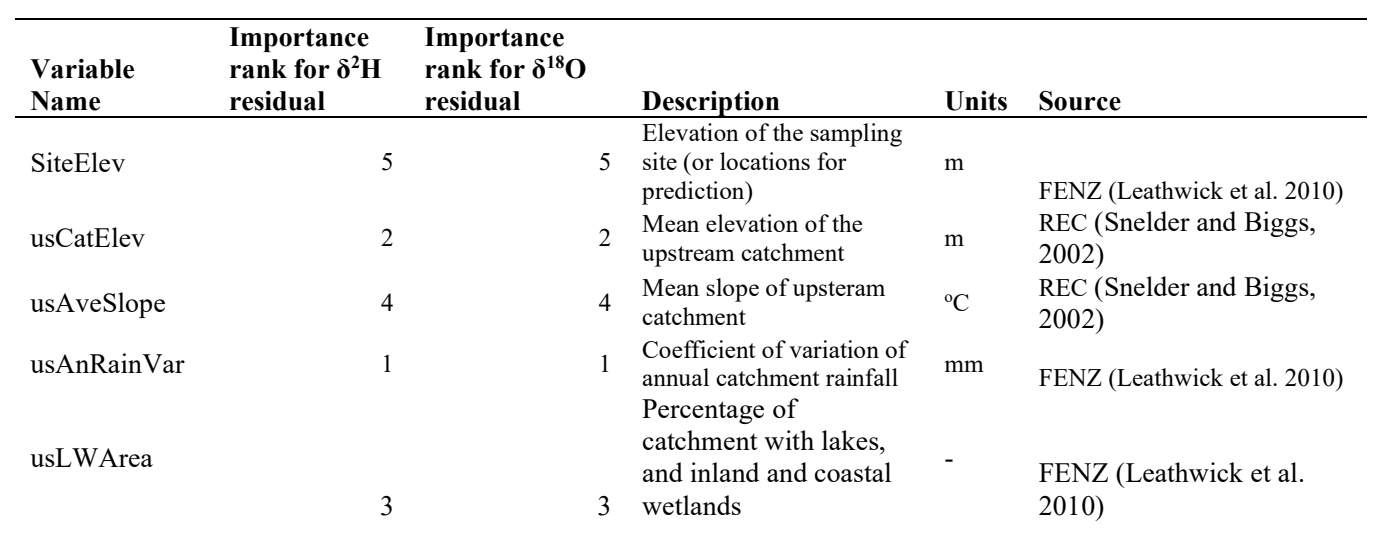

